\title{
Changing trends in residents-as-teachers across graduate medical education
}

This article was published in the following Dove Press journal:

Advances in Medical Education and Practice

28 April 2017

Number of times this article has been viewed

\author{
Morhaf Al Achkar' \\ Mathew Hanauer' \\ Elizabeth $\mathrm{H}$ Morrison ${ }^{2}$ \\ M Kelly Davies' \\ Robert $\mathrm{COh}^{3}$ \\ 'Department of Family Medicine- \\ Indiana University, Indianapolis, IN, \\ USA; ${ }^{2}$ Health Sciences, University \\ of California, Riverside School \\ of Medicine, Riverside, CA, USA; \\ ${ }^{3}$ Family Medicine, Uniformed Services \\ University of the Health Sciences, \\ Bethesda, MD, USA
}

Background: Teaching residents how to teach is a critical part of residents' training in graduate medical education (GME). The purpose of this study was to assess the change in resident-asteacher (RaT) instruction in GME over the past 15 years in the US.

Methods: We used a quantitative and qualitative survey of all program directors (PDs) across specialties. We compared our findings with a previous work from 2000-2001 that studied the same matter. Finally, we qualitatively analyzed PDs' responses regarding the reasons for implementing and not implementing RaT instruction.

Results: Two hundred and twenty-one PDs completed the survey, which yields a response rate of $12.6 \%$. Over $80 \%$ of PDs implement RaT, an increase of $26.34 \%$ compared to $2000-2001$. RaT instruction uses multiple methods with didactic lectures reported as the most common, followed by role playing in simulated environments, then observing and giving feedback. Residents giving feedback, clinical supervision, and bedside teaching were the top three targeted skills. Through our qualitative analysis we identified five main reasons for implementing RaT: teaching is part of the residents' role; learners desire formal RaT training; regulatory bodies require RaT training; RaT improves residents' education; and RaT prepares residents for their current and future roles.

Conclusion: The use of RaT instruction has increased significantly in GME. More and more PDs are realizing its importance in the residents' formative training experience. Future studies should examine the effectiveness of each method for RaT instruction.

Keywords: resident as teachers, RaT, graduate medical education, GME, survey

\section{Background}

Teaching residents how to teach is increasingly recognized as a critical part of residents' training in graduate medical education (GME). ${ }^{1}$ In addition to teaching medical students, residents supervise their junior peers and educate patients..$^{2-4}$ Residents with better teaching skills seem to have a greater content knowledge and better clinical skills. ${ }^{5}$ Recognizing the important role of residents as teachers, the Accreditation Council for Graduate Medical Education (ACGME) and the Liaison Committee on Medical Education (LCME) emphasize the need for structured programs to enhance residents' teaching skills. ${ }^{6-8}$

More and more, residency programs are adopting residents-as-teachers (RaT) curricula to formally train residents to teach. ${ }^{9}$ In addition to the awareness of residents' role as teachers, residency programs and medical schools are required by the ACGME and LCME to formally train residents in such skills as part of maintaining accreditation. ${ }^{10,11}$ To fulfill these requirements, RaT has been delivered using many methods, 
including lectures, small-group discussion, practice with peers, videotape reflections, and role-playing. ${ }^{9}$

During 2000-2001, a survey was sent to all ACGMEaccredited residencies to clarify the prevalence and characteristics of RaT instruction. ${ }^{12}$ Overall, 55\% of the surveyed residency directors offered formal RaT instruction. Lectures, workshops, and small-group interactions prevailed as the typical instructional format. In 2014, we pilot surveyed the family medicine (FM) residency program directors (PDs) in the US. ${ }^{13}$ More than $85 \%$ of FM residency programs surveyed offered RaT programs, compared to $52.5 \%$ in 2001. Lectures were the most commonly used format, followed by facilitated interaction and workshops. ${ }^{13}$

This study built on our pilot work in FM and assessed the change in using RaT curricula in GME in the US. We compared the prevalence of RaT curricula, examined trends using different formats of delivery, assessed the PDs' attitude toward RaT training, and, finally, examined the perceived barriers to RaT implementation. Importantly, the study qualitatively explored the reasons for implementing and not implementing RaT instructions.

\section{Methods}

\section{Design}

We used RedCap ${ }^{\circledR}$ to survey all the PDs listed in directory of the ACGME in the following specialties: FM, psychiatry, obstetrics and gynecology $(\mathrm{OB} / \mathrm{GYN})$, pediatrics, internal medicine (IM), emergency medicine (EM), and surgery. We modified a previous national survey on RaT to better fit the style of the survey questions and the aims of the study. ${ }^{12-15}$ In addition to demographic questions, the survey consisted of check-all-answers questions and open-ended questions. PDs received an email invitation to participate, followed by three other email reminders 5 days apart.

In this survey we included a question on the mode of intervention (longitudinal vs single intervention). In addition, we included a question on targeted skills and content area, a main focus for this study that was not considered in previous works. Furthermore, we asked whether interventions were offered in collaboration with other ACGME programs. We also included open-ended questions to understand the reasons and barriers for implementing RaT. Finally, we asked similar questions to all PDs whether they currently have RaT experience or only contemplating such experience in the future. The Indiana University Institutional Review Board approved this study as exempt from full review and waived the need for informed consent. Participants received a study information sheet.

\section{Participants}

We identified 1,757 PDs and were able to validate the email addresses of 1,479 (84.18\%) potential participants through their residency websites. The remaining email addresses were either generic or coordinators' email addresses. The overall response rate was $12.6 \%(\mathrm{n}=221)$.

\section{Statistical analysis}

We utilized descriptive statistics with frequency counts and percentages for categorical variables, as well as mean values and standard deviations for continuous variables to describe the characteristics of respondents who implement and do not implement RaT. To understand the characteristics related to programs that implement RaT, we developed a logistic regression model where the dependent variable was an indicator variable that takes the value of 1 if the program is currently implementing RaT instruction and the value of 0 if the program is currently not implementing RaT instruction. ${ }^{16}$ In the initial model, we included all covariates ( 24 variables) related to the residency and the PD characteristics to identify factors associated with implementing RaT instructions. Using stepwise logistic regression, ${ }^{17}$ the model was reduced to include only fifteen covariates. To compare our results with those of Morrison et al's, ${ }^{2}$ we used Student's $t$-test for continuous variables and chi-square for categorical ones.

\section{Qualitative analysis}

We used a thematic approach to data coding and analysis and chose to utilize line-by-line free form coding. ${ }^{18}$ This type of coding fits the study's exploratory nature. To improve the codes' validity, we included a peer-debriefed process into the analysis. A peer debriefer is a colleague who critically analyzes the codes for issues such as over- and under-emphasized points and vague descriptions. ${ }^{19}$

\section{Results}

\section{Prevalence of $\operatorname{RaT}$}

The characteristics of the residency programs and the PDs are included in Table 1. Among the respondents, 178 (80.54\%) reported providing $\mathrm{RaT}$ instruction. This represents a $26.34 \%$ increase (95\% CI 20.39-32.29\%) from 2001. A vast majority of PDs (83.4\%) reported that instruction is offered only for their own residents.

The prevalence of RaT varied by program type, the size of the community, and the specialty. Characteristics associated with a lower prevalence of RaT included university-affiliated community-based programs (OR $0.30 ; 95 \%$ CI $0.10-0.88$ ), community-based non-university-affiliated programs (OR 
Table I Residency program and program director characteristics and RaT prevalence

\begin{tabular}{|c|c|c|c|c|}
\hline Characteristics & Frequency & Percentage & Has RaT & Percentage \\
\hline \multicolumn{5}{|l|}{ Type of program } \\
\hline University-based & 97 & 43.89 & 87 & 89.69 \\
\hline Community-based, university-affiliated & 93 & 42.08 & 70 & 75.27 \\
\hline Community-based, non-affiliated & 26 & 11.76 & 17 & 65.38 \\
\hline Military & 4 & 1.81 & 3 & 75 \\
\hline Other & 1 & 0.45 & 1 & 100 \\
\hline \multicolumn{5}{|l|}{ Specialty } \\
\hline Emergency medicine & 26 & 11.76 & 23 & 88.46 \\
\hline Family medicine & 59 & 26.7 & 48 & 81.36 \\
\hline Internal medicine & 45 & 20.36 & 37 & 82.22 \\
\hline Obstetrics/gynecology & 22 & 9.95 & 18 & 81.82 \\
\hline Psychiatry & 14 & 6.33 & 12 & 85.71 \\
\hline Surgery & 21 & 9.5 & 9 & 42.86 \\
\hline Pediatrics & 34 & 15.38 & 31 & 91.18 \\
\hline \multicolumn{5}{|l|}{ Community size } \\
\hline$<30,000$ & 3 & 1.36 & 3 & 100 \\
\hline $30,000-74,999$ & 16 & 7.24 & 14 & 87.5 \\
\hline $75,000-149,999$ & 32 & 14.48 & 22 & 68.75 \\
\hline $150,000-499,999$ & 53 & 23.98 & 45 & 84.91 \\
\hline $500,000-1$ million & 39 & 17.65 & 33 & 84.62 \\
\hline$>$ I million & 78 & 35.29 & 61 & 78.21 \\
\hline \multicolumn{5}{|l|}{ Proportion of non-US graduates } \\
\hline $0-24 \%$ & 129 & 58.37 & 106 & 82.17 \\
\hline $25-49 \%$ & 21 & 9.5 & 19 & 90.48 \\
\hline $50-74 \%$ & 21 & 9.5 & 16 & 76.19 \\
\hline $75-100 \%$ & 48 & 21.72 & 36 & 75 \\
\hline Do not know & 1 & 0.45 & 0 & 0 \\
\hline No answer & 1 & 0.45 & 1 & 100 \\
\hline \multicolumn{5}{|l|}{ Gender } \\
\hline Male & 132 & 59.73 & 99 & 75 \\
\hline Female & 87 & 39.37 & 78 & 89.66 \\
\hline No answer & 2 & 0.9 & 1 & 50 \\
\hline \multicolumn{5}{|l|}{ Region (USA) } \\
\hline Midwest & 61 & 27.6 & 49 & 80.33 \\
\hline Northeast & 58 & 26.24 & 46 & 79.31 \\
\hline South & 58 & 26.24 & 50 & 86.21 \\
\hline West & 33 & 14.93 & 23 & 69.7 \\
\hline \multirow[t]{2}{*}{ No answer } & 11 & 4.98 & 10 & 90.91 \\
\hline & Mean & SD & & \\
\hline Years since program started & 43.91 & 21.53 & & \\
\hline Years as a program director & 6.8 & 5.7 & & \\
\hline
\end{tabular}

Abbreviations: RaT, resident-as-teacher; SD, standard deviation.

0.13 ; $95 \%$ CI $0.03-0.52$ ), programs located at mid-size communities (OR $0.32 ; 95 \%$ CI $0.11-0.91$ ), and surgery programs (OR $0.02 ; 95 \%$ CI $0.00-0.23$ ). Table 2 presents the variables included in the logistic regression model with the variables' odds ratios. Figure 1 shows the relevance of RaT instruction by specialty.

The total number of hours dedicated to RaT instruction varied widely among programs. The mean was 24.37 hours (standard deviation [SD] 69.07) and the median was 11 hours. This represents a 12.96 hours increase (95\% CI 8.71-17.20) compared to 2001, when the average hours was 11.41 (SD $11.41)$ and the median was 8 hours. The difference between specialties was also broad in terms of number of hours. Pediatrics reported the longest duration of time ( 56.33 hours) and surgery reported the shortest ( 8.7 hours) devoted to RaT. RaT was offered as a single intervention by $52.25 \%(n=93)$ of respondents. Compared to 2001, single, one-time sessions decreased significantly from $74.48 \%$ to $52.25 \%$ (OR $37.48 \%$; 95\% CI 25.83-54.39\%).

RaT instruction utilized multiple methods with didactic lectures were reported as the most commonly used form (91.57\%), followed by role playing in simulated environments (62.92\%) and observing and giving feedback as residents work with learners (60.67\%). Assigned reading (23.03\%) and online modules 
Table 2 Residency program and program director characteristics and their association with RaT.

\begin{tabular}{llll}
\hline Program characteristics & $\begin{array}{l}\text { Odds } \\
\text { ratio }\end{array}$ & $\mathbf{p}$-Value & $\mathbf{( 9 5 \% ~ C l )}$ \\
\hline Years as a program director & 1.04 & 0.36 & $(0.96-1.12 \%)$ \\
Southern region & 1.78 & 0.29 & $(0.61-5.16 \%)$ \\
Emergency Medicine & 0.27 & 0.3 & $(0.02-3.16 \%)$ \\
Family Medicine & 0.27 & 0.25 & $(0.03-2.52 \%)$ \\
Internal Medicine & 0.36 & 0.39 & $(0.03-3.75 \%)$ \\
Obstetrics/Gynecology & 0.12 & 0.1 & $(0.01-1.50 \%)$ \\
Psychiatry & 0.25 & 0.33 & $(0.02-4.1 \%)$ \\
Surgery* & $0.02 *$ & 0.00 & $(0.00-0.23 \%)$ \\
Proportion of non-US graduates & 2.70 & 0.17 & $(0.65-11.20 \%)$ \\
0-24\% & & & \\
Proportion of non-US graduates & 7.60 & 0.06 & $(0.94-61.23)$ \\
25-49\% & & & \\
Proportion of non-US graduates & 2.49 & 0.27 & $(0.50-12.46 \%)$ \\
75-I00\% & & & \\
Community-based, & $0.30^{*}$ & 0.03 & $(0.10-0.88 \%)$ \\
university-affiliated* & & & \\
Community-based, non-affiliated* & $0.13^{*}$ & 0.00 & $(0.03-0.52 \%)$ \\
Male & 0.58 & 0.3 & $(0.21-1.62 \%)$ \\
Community size & $0.32^{*}$ & 0.03 & 0.11 \\
$75,000-149,999 *$ & & & \\
\hline Note & & &
\end{tabular}

Note: $*$-value $<0.05$.

Abbreviations: $\mathrm{RaT}$, resident-as-teacher; $\mathrm{Cl}$ confidence interval.
$(17.98 \%)$ were the least frequently used form. In comparison, in 2001 , lectures on teaching skills came first (63.92\%), then facilitated interactive discussion in small or large groups (48.89\%), followed by role playing or simulation ( $40.50 \%$ ), and critiquing residents during or after actual teaching encounters (35.13\%). Figure 2 presents the changes in trend of RaT formats.

\section{Targeted skills and content areas in teaching instruction}

PDs rated the importance of certain targeted skills and content areas on a scale of 1 , "of no importance at all" to 5, "of highest importance." The proportion of PDs who gave ratings of 4 or 5 is presented in Figure 3. Giving feedback (90.86\%), clinical supervision ( $85.63 \%)$, and bedside teaching $(81.71 \%)$ were the top three items. Classroom lecturing skills received the lowest rating $(39.54 \%)$.

\section{Contemplated RaT experiences}

Among the residencies that do not currently have RaT instruction, $53.49 \%(\mathrm{n}=23)$ were interested in implementing some form of instruction. PDs reported that a future instruction would be longitudinal in the majority of cases

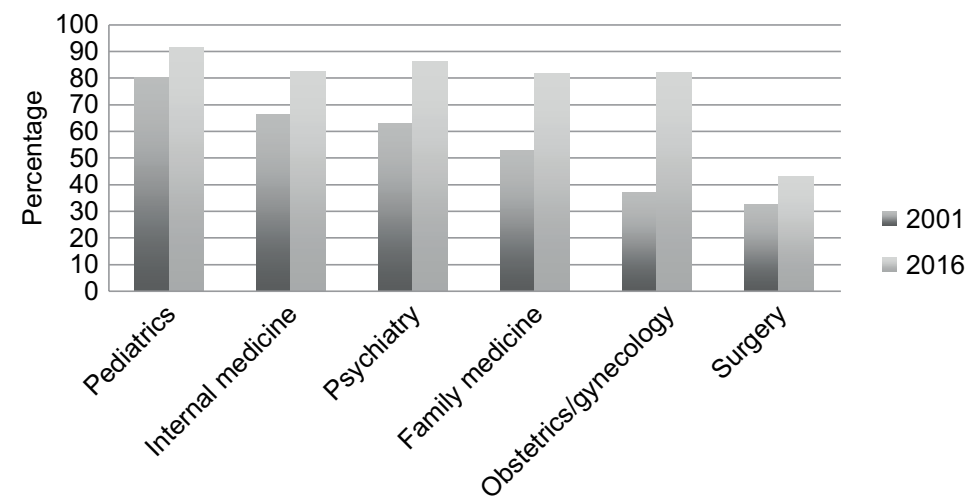

Figure I Prevalence of RaT instruction by specialty.

Abbreviation: RaT, resident-as-teacher.

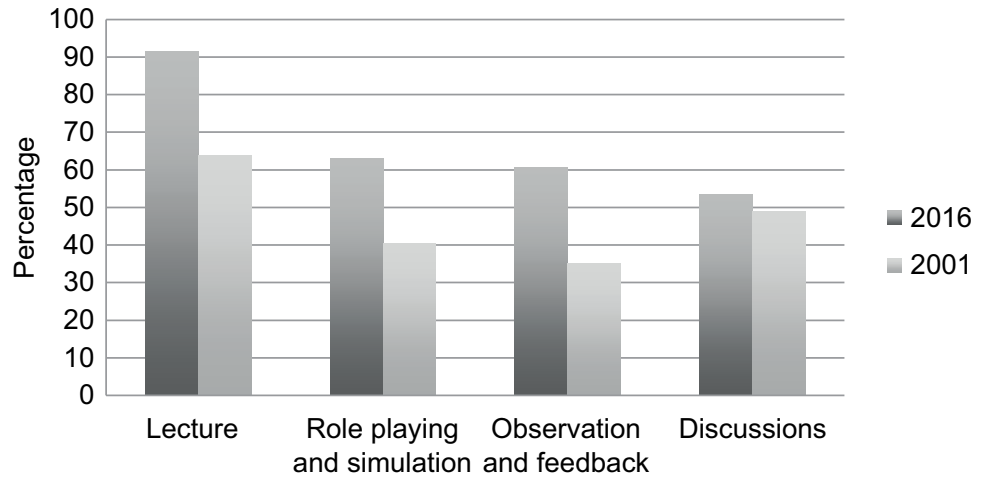

Figure 2 Formats of RaT instruction in $200 \mathrm{I}$ and in 2006.

Abbreviation: RaT, resident-as-teacher. 


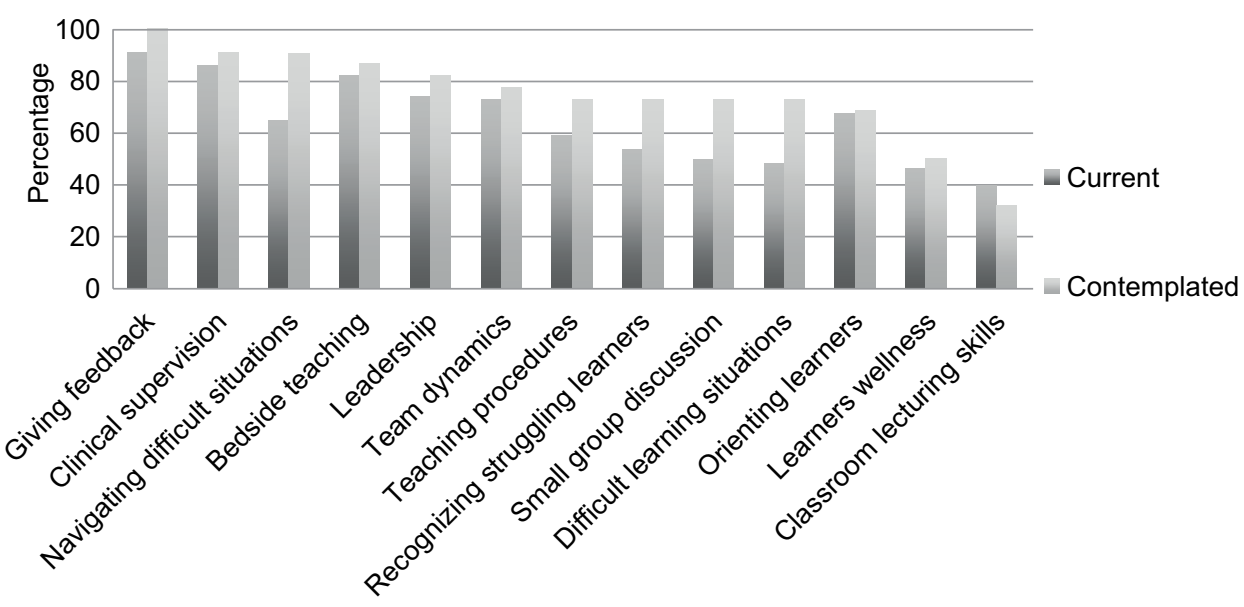

Figure 3 Targeted skills and content areas.

$(65.22 \%)$. The median number of hours would be dedicated for RaT is 12 hours. PDs reported they would use a combination of role-playing in a simulated environment (78.26\%), didactic lectures (69.57\%), observing and giving residents feedback while they work with residents (69.57\%), and facilitated interaction discussions (60.87\%), among others. The instruction would potentially be in collaboration with other residencies $(21.74 \%)$ while the rest would deliver the instruction to their own residents only. Figure 3 shows the ranking of importance of the targeted skills and content areas for programs contemplating RaT in comparison to the ones that currently have RaT. The top ranked items were giving feedback (100\%), clinical supervision (90.91\%), and navigating difficult situations $(90.48 \%)$.

\section{Results of qualitative analysis: reasons for implementing $\mathrm{RaT}$}

After conducting the thematic analysis, we identified five main reasons for implementing RaT: (1) teaching is part of the residents' role; (2) learners desire formal RaT training; (3) regulatory bodies require RaT training; (4) RaT improves residents' education; and (5) RaT prepares residents for their current and future roles. Below we provide explanations for each of these themes as well as a quote that best explains the identified theme.

\section{Teaching is part of the residents' role}

Residents teach as part of their responsibilities in the learning and caring for their patients. Residents teach their colleagues and their peers, junior residents and medical students, patients and their families, and other learners, such as physician assistants and nurse practitioner students. All these teaching, supervising, and team-leading tasks are emphasized in residents as teacher programs. PDs said the following in their responses:

Doctors are docents. [Psychiatry PD]

Residents are expected to supervise junior learners and teach them. [EM PD]

They are the front-line with medical students. [Pediatrics PD]

\section{Learners desire formal RaT training}

PDs perceive that both residents and students desire formal instruction in teaching. In fact, learner satisfaction was cited as the motivation to provide such instruction. Furthermore, RaT was viewed as an attractive feature that could help recruit students to the residency program. Again, from the PDs:

Both the students and residents love it. [EM PD]

To enhance learner satisfaction and to continue to have excellent recruitment into the field. [OB/GYN PD]

Regulatory bodies require RaT training

When asked about the reason for implementing RaT, some PDs referred to the ACGME requiring all residencies to provide $\mathrm{RaT}$ instruction to their trainees. Additionally, some referred to the LCME also requiring that all residents and fellows working with medical students receive RaT training. PDs also identified university-specific accreditation standards or citations issued to the affiliated medical school as the primary motivation for providing RaT training. 


\section{RaT instruction improves residents' education}

For the majority of PDs, the reason to implement RaT is to improve residents' education. PDs also believe that RaT instruction improves residents' knowledge of content. It enhances their skills in communication, leadership, supervision, and teamwork, in addition to directly improving teaching skills. This instruction also advances their personal growth by helping them understand themselves better as learners. RaT instruction is thought to improve the overall quality of the program, which thereby improves the quality of student experience and their satisfaction on rotations. Finally, by improving teaching, PDs report that patient care improves, as residents become better clinicians. From the PD responses:

To develop leadership, communication and teaching skills among pediatric resident. [Pediatrics PD]

Enhance junior resident, medical student, and patient education skills. [FM PD]

It helps them understand more about themselves as learners as well. [FM PD]

Improve learning by improving teaching for both learner and teacher. [IM PD]

\section{RaT prepares residents for their current and future roles}

As previously noted, RaT programs are implemented to prepare residents for their roles in teaching and supervising. They are particularly important to prepare residents to transition to more senior roles. For some PDs, the reason to implement RaT is to help residents in their transition to academic careers as faculty members or to attain further training in fellowships:

To better prepare trainees for that role. [Pediatrics PD]

Prepare interns for senior year and prepare seniors for the upcoming year. [FM PD]

To help with future fellowship responsibilities. [IM PD]

Prepare people to be teaching faculty. [FM PD]

\section{Reasons for not implementing RaT}

The PDs who do not currently have RaT were asked why they did not implement such instruction. Five reasons emerged in the analysis: (1) lacking time and energy; (2) lacking expertise and resources; (3) being a new program; (4) limited access to students; and (5) RaT instruction is not desired.

\section{Lacking time and energy}

The primary reason for not providing RaT was time and energy, primarily because of competing demands related to duty hours restrictions.

Too many competing demands. [IM PD]

ACGME hours restriction and other conferences. [IM PD]

Time would be spent away from the operating room. [Surgery PD]

Space in the curriculum. [FM PD]

Time and energy. [Psychiatry PD]

\section{Lacking expertise and resources}

PDs cited a lack of resources in terms of faculty members who could lead the training as a main barrier to providing RaT:

Expertise in teaching the subjects. [Pediatrics PD]

Limited faculty resources to provide such instruction. [OB/

GYN PD]

\section{Being a new program}

A few programs attributed not providing RaT to being new:

New program; on the "to do list". [Psychiatry PD]

\section{Limited access to students}

A few programs reported having limited access to students as the primary reason for not providing $\mathrm{RaT}$ :

Limited interaction with medical students or other learners at our institution. [OB/GYN PD]

\section{$\mathrm{RaT}$ instruction is not desired}

PDs felt RaT was not needed because they perceived residents are not interested or their programs provide informal alternatives:

Not felt to be needed. [Surgery PD]

They are already aware of teaching students. [Surgery PD]

Most residents not interested. [FM PD]

We guide residents on our expectations for their work with students but we do not have a set curriculum. [FM PD]

\section{Discussion}

The use of RaT instruction has increased more than 25\% across ACGME residencies over the past 16 years. ${ }^{15}$ The hours invested in learning these teaching skills have also 
increased..$^{15}$ In our study, PDs provide some evidence on the reasons for this expansion. Graduate medical educators report that teaching is an essential part of a residents' role. Residents and other learners have positive attitudes toward RaT instruction and they desire it. Furthermore, regulatory bodies, such as the ACGME and the LCME, as well as universities have set clear expectations regarding preparing residents to teach. In addition, $\mathrm{RaT}$ instruction has been viewed as an effective way to improve the entire educational experience for residents and prepare them to transition between the phases of their training and their future careers.

While RaT instruction is increasing, some programs still do not provide it. Resources, especially the expertise to lead the instruction, are not distributed equally among residencies. ${ }^{15}$ While university programs can often leverage the available academic faculty and faculty development opportunities, smaller community programs may not have these resources. The overwhelming majority of programs across specialties provide RaT instruction; however, surgery PDs reported lower prevalence of RaT instruction. It is not clear why, but it may be related to under-reporting or RaT may be valued less in a surgical specialty than other specialties. Further research may help explain the difference between specialties in terms of time and efforts dedicated for RaT instruction.

Unfortunately there is little evidence of RaT instruction delivered in collaboration between programs. However, we have recently shown, in a work submitted for publication, that more than $60 \%$ of residency programs across GME provide interprofessional education (IPE) experiences to their residents. ${ }^{20}$ IPE has become increasingly recognized for its role in promoting collaboration and teamwork, both of which are critical components of a resident's education. Teaching is a generic skill, and teaching instruction represents an opportunity for centrally acting GME offices to take the lead by providing these experiences to residents - either at the start of their internship or at the beginning of their second year.

An innovative side of this study included exploring aspects of the programs that currently do not have RaT instruction. We aimed to explore their reasons for not implementing RaT instruction and whether they were contemplating their implementation. It is interesting to note that some of the reasons the PDs cited for not implementing RaT were inconsistent with what is reported by programs who have RaT instruction. For example, the assumed residents' interest and lack of interest were cited by the two groups as justification for implementing and not implementing of RaT instruction, respectively.
Didactic lecturing continues to be the main mode of instruction over the past 16 years. However, it is promising that residencies are using more diverse methods of instruction, particularly active methods, such as role-playing and observation/feedback. A large body of literature supports experiential learning - in which learners are engaged in activities resembling the actual task or providing feedback/ reflection on the performed task - as a key method for adult learning. While lectures and class learning, in general, are efficient ways to cover content, educational researchers have repeatedly questioned their effectiveness even for information retention. Residents have different learning styles, and the "one-size-fits-all" lecturing approach lacks engagement for adult learners.

Our study has several strengths. We updated the literature on RaT prevalence, formats, and targeted skills, as well as the reasons for implementing and not implementing RaT instruction. The use of a mixed-method approach is particularly powerful in understanding this subject matter. While quantitative-type questions are important for measuring the prevalence of RaT and assessing priorities when it comes to formats and skills, qualitative open-ended questions allow researchers to dig deeper into beyond the numbers into gauging attitudes and exploring the reasons behind behaviors. In contrast to closed-ended ones, the open-ended questions allowed participants the freedom to visit areas that may not have been considered when designing the survey questions. Leveraging the actual individual program data from the Morrison et al 2000-2001 study is powerful to capture changing trends. ${ }^{2}$ In addition, using many of the same questions allowed us to directly compare the trends we identified with the results from previous studies in order to assess whether the trends continued or changed over time.

Our study is not without limitations. The response rate was particularly low, which is not surprising for a survey that involved busy PDs. Furthermore, inherent in the nature of cross-sectional surveys; our study is susceptible to selection bias and reporting bias. The fact that our findings were consistent with the results from our previous pilot work supports the validity of this study..$^{13}$ Another related issue is the varied response rate between specialties. Despite these limitations, our study provides an overview of the specific formats of instruction and types of skills used across ACGME programs even though we were not able to identify these types for each individual specialty due to the smaller sample size. Finally, since we only explored the current practices in RaT instruction, little can be concluded about the effectiveness of any particular mode of instruction or about the relevance of 
any targeted skill. Further studies comparing the effectiveness of one RaT design against another will be particularly important for ensuring that the instruction used is actually effective and leading to the desired goals.

\section{Acknowledgments}

The study was funded by the American Academy of Family Physicians Foundation.

The opinions herein are those of the authors. They do not reflect official policy of the Uniformed Services University, the Department of the Army, or the Department of Defense.

The authors would like to acknowledge the help of Mike Busha, Aloysius Humbert, and Abigail Litwiller for their help reviewing the survey instrument.

\section{Disclosure}

The authors report no conflicts of interest in this work.

\section{References}

1. Bree KK, Whicker SA, Fromme HB, Paik S, Greenberg L. Residentsas-teachers publications: what can programs learn from the literature when starting a new or refining an established curriculum? J Grad Med Educ. 2014;6:237-248.

2. Morrison EH, Friedland JA, Boker J, Rucker L, Hollingshead J, Murata P. Residents-as-teachers training in U.S. residency programs and offices of graduate medical education. Acad Med. 2001;76(10):S1-S4.

3. Greenberg LW, Goldberg RM, Jewett LS. Teaching in the clinical setting: factors influencing residents' perceptions, confidence and behavior. Med Educ. 1984;18:360-365.

4. Hill AG, Srinivasa S, Hawken SJ, et al. Impact of a resident-as-teacher workshop on teaching behavior of interns and learning outcomes of medical students. J Grad Med Educ. 2012;4(1):34-41.
5. Falcone JL, Ferson PF, Hamad GG. S/he who can, does and teaches. S/ he who cannot, doesn't. J Surg Educ. 2014;71(1):96-101.

6. Karani R, Fromme HB, Cayea D, Muller D, Schwartz A, Harris IB. How medical students learn from residents in the workplace: a qualitative study. Acad Med. 2014;89(3):490-496.

7. Liaison Committee on Medical Education. Functions and Structure of a Medical School. Available from: https://med.virginia.edu/umecurriculum/wp-content/uploads/sites/216/2016/07/2017-18_Functionsand-Structure_2016-03-24.pdf. Accessed December 19, 2014.

8. Accreditation Council for Graduate Medical Education and The American board of Family Medicine. The Family Medicine Milestone Project. Available from http://www.acgme.org/acgmeweb/Portals/0/PDFs/Milestones/FamilyMedicineMilestones.pdf. Accessed December 19, 2014.

9. Rivera V, Yukawa M, Aronson L, Widera E. Teaching geriatric fellows how to teach: a needs assessment targeting geriatrics fellowship program directors. J Am Geriatr Soc. 2014;62(12):2377-2382.

10. Silva D, Lewis KO. Assessment of medical residents technology readiness for an online residents-as-teachers curriculum. P R Health Sci J. 2014; 33(2):51-57.

11. Hunt D, Migdal M, Eaglen R, Barzansky B, Sabalis R. The unintended consequences of clarity: reviewing the actions of the Liaison Committee on Medical Education before and after the reformatting of accreditation standards. Acad Med. 2012;87(5):560-566.

12. Morrison EH, Hafler JP. Yesterday a learner, today a teacher too: residents as teachers in 2000. Pediatrics. 2000;105:238-241.

13. Al Achkar M, Davies MK, Busha M, Oh R. Resident-as-teacher in family medicine: A CERA survey. Fam Med. 2015;47(6):452-458.

14. Bing-You RG, Tooker J. Teaching skills improvement programs in US internal medicine residencies. Med Educ. 1993;27:259-65.

15. Ng VK, Burke CA, Narula A. Residents as teachers: survey of Canadian family medicine residents. Can Fam Physician. 2013;59(9):421-427.

16. Agresti, 2013. Categorical Data Analysis. 3rd ed. New York: Wiley; 2012

17. Tabachnick BG, Fidell LS. Using Multivariate Statistics. 6th ed. Boston: Pearson; 2012.

18. Charmaz K. Constructing Grounded Theory: A Practical Guide Through Qualitative Analysis. 2nd ed. Thousand Oaks, CA: Sage; 2014.

19. Lincoln YS, Guba EG. Naturalistic Inquiry. 1st ed. Newbury Park, CA: Sage Publications; 1985.
Advances in Medical Education and Practice

\section{Publish your work in this journal}

Advances in Medical Education and Practice is an international, peerreviewed, open access journal that aims to present and publish research on Medical Education covering medical, dental, nursing and allied health care professional education. The journal covers undergraduate education, postgraduate training and continuing medical education

\section{Dovepress}

including emerging trends and innovative models linking education, research, and health care services. The manuscript management system is completely online and includes a very quick and fair peer-review system. Visit http://www.dovepress.com/testimonials.php to read real quotes from published authors. 